\title{
Corpo problema Considerações sobre a forma e sua política nas artes performativas
}

\author{
Né Barros
}

Sabemos que os caminhos podem ser diversos quando pretendemos pensar a dança na sua expressão contemporânea. As perguntas que podemos colocar na formulação dessa discussão podem ser das mais resistentes - o que mudou de tão radical na dança de hoje? - até às mais apocalípticas - terá perdido a dança os seus gestos? Desde uma abordagem onde se pretenderá indagar a dança nos seus fundamentos, na sua ontologia, até a um questionamento mais contextual, para ambas as vias referidas trata-se de encontrar os melhores eixos que possam responder de forma satisfatória ao modo como a dança tem evoluido ou se tem transformado nas suas poéticas e na sua função comunicativa.

A nossa hipótese é que um dos eixos orientadores da transformação da evolução da dança consiste em considerar o corpo "como um problema". Não no sentido estrito da problematização teórica do corpo (anatómico, simbólico, antropológico, estético, etc.), mas sim no sentido da determinação de um "corpo-problema" enquanto axioma teórico aplicável ao campo da dança na sua praxis e na sua crítica. É através do enquadramento geral do corpo como um problema que a dança renasce e surge como um novo mundo com problemas antes impensados. Sucintamente, a nossa hipótese considera um espaço abstrato que se abre quando se pretende explorarem os gestos e as ações de um corpo. Este espaço abstrato nascido na intuição (no confronto perante o outro ou perante nós próprios) ou com base num conhecimento pro-histórico (um posicionamento perante a arte), dizíamos, esse espaço abstrato requer-se antes da mensagem, na formulação não formulada, no problema indeterminado. 0 corpo problema é, assim, como um atractor que poderá ser tomado como uma função teleológica no fazer da obra em si.

\section{Corpo como um problema}

Uma das primeiras ilações deste corpo-problema é entendêlo como uma suspensão relativamente ao mundo a que pertence, à sua expressão mundana ou trivial. Trata-se de repensar o corpo-problema enquanto suspensão, frenagem ou obstáculo relativo a um dado curso. Há um passo atrás no que aconteceu, há a consciência do gesto que agora é "evento". Com esta suspensão, ou fratura, ou mesmo desconstrução, é um novo corpo que surge, é um corpo extraído a um vórtice de imagem e ritmo para se tornar o corpo do "porvir". Esta descolagem do corpo com as suas possiveis representações com o objetivo de lhe encontrar novas aberturas, de o "diferir", implica que este corpo-problema esteja antes da mensagem. Nesta desvinculação, o corpo-problema reencontra-se num regime geral estético enquanto recorte de um espaço específico do sensivel onde pode produzir os seus dissensos e ficções, ou agenciar relações heterogéneas do sensivel. Este regime não é, porém, exclusivo da estética, é também o da política, já que ambas assumem formas comuns de partilha do sensivel, como Jacques Rancière tem ajudado a clarificar: as formas que assumem a distribuição do tempo, do espaço e das atividades do sujeito (dos modos de pensar, fazer e sentir). Para Rancière a estética e a política são maneiras de organizar o sensivel, isto é, nas suas palavras, de dar a entender, de dar a ver, de construir a visibilidade e a inteligibilidade dos acontecimentos. Há algo de permanente no regime estético de Rancière e que implica uma suspensão das formas triviais da experiência e um processo de depuração. Não se trata, segundo o autor, de nada de radicalmente novo ou de encontrar momentos históricos de identificação de esteticização do poder. Há que distinguir representação jurídica da representação estética, discernir uma comunidade política como um grupo de indivíduos governados por um poder ou uma comunidade como um organismo animado. É neste recorte espácio-temporal e respetiva configuração sensória que previamente a política, assim como a estética, deve ser pensada. Ao refletir sobre estética e política, Rancière não pretende regressar a questões como as da ideologia na arte, a das relações entre arte e o mercado ou as do empenhamento político da arte.

[A arte] é política antes de mais nada pela maneira como configura um sensorium espaço-temporal que determina maneiras do estar junto ou separado, fora ou dentro, face a ou no meio de... Ela é política enquanto recorta um determinado espaço ou um determinado tempo, enquanto os objetos com os quais ela povoa este espaço ou o ritmo que ela confere a esse tempo determinam uma forma de experiência especifica, em conformidade ou em ruptura com outras: uma forma especifica de visibilidade, uma modificação das relações entre formas sensiveis e regimes de significação, velocidades específicas, mas também e antes de mais nada formas de reunião ou de solidão. (Rancière 2005: 2) 


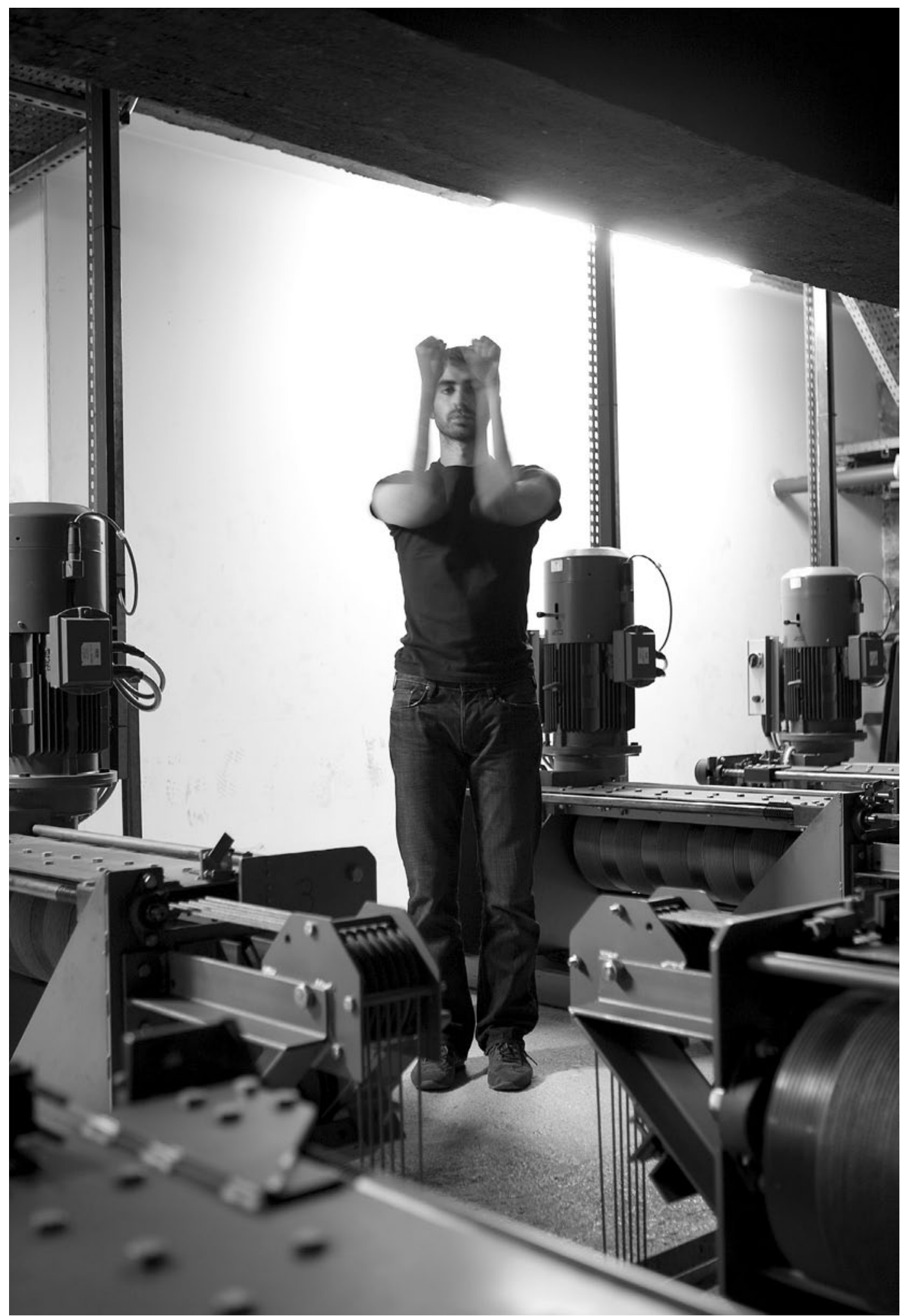

Story Case,

coreog. Né Barros, 2009,

fot. Cesário Alves.
A arte é política e tem a sua política própria que, segundo o autor, não só faz concorrência à outra como também se antecipa às vontades dos artistas. Por um lado, a arte assegura de tal modo a sua autonomia que deixa de haver fronteiras entre arte e não-arte; por outro lado, esta suspensão da experiência quotidiana corresponde à prefiguração do paradigma dum novo mundo "comum", o comum que está para construir e não o que é dado como tal. Por isso, mais do que a arte consubstanciada nas obras, interessa ao autor as formas de visibilidade e de pensabilidade e a sua relação com as práticas na arte. Para tal Rancière refere três regimes de identificação da arte: regime ético das imagens, regime poético ou representativo da arte e regime estético da arte. Sendo que, sucintamente, o regime ético das imagens conta o representado e não o processo de representação, enquanto o regime poético ou representativo da arte trata da relação balanceada entre o polo representado e o polo do 
representante, funcionando como critério essencial o processo representativo fundado na ideia de adequação.

Numa abordagem de um regime estético, o corpoproblema é também um corpo da indiferença onde a dança, ao mesmo tempo que encontra a sua imobilidade, encontra também todos os gestos possiveis. 0 "problema", aqui, equivale-se à "complexidade" e à qual será necessário responder posteriormente. Nesta dimensão ontológica, a dança parece encontrar a sua quase-impossibilidade de ser, mas é precisamente neste movimento que a dança encontra uma nova saída e se transforma. 0 mais provável é que esta transmutação do gesto - que doravante se implica numa conceção do dançante - se possa equivaler a uma espécie de questionamento sobre o corpo na dança tendo por objetivo o próprio retorno ao corpo. Uma duplicação e a promessa de um novo corpo.

\section{0 produto: fora e dentro das intencionalidades}

0 espaço solitário que se desenha para este corpoproblema, enquanto espaço da indiferenciação, é também o espaço da sua autonomia. É no grau em que o corpoproblema é produto que gera o impensado que se percebe o horizonte da sua autonomia. Se anteriormente tínhamos colocado o corpo-problema num lugar de suspensão, num aquém corpo-mensagem, agora há que revê-lo como "produto" quer na sua tangibilidade material (corpo em performance) quer imaterial (corpus teórico, o problema agora formulado). Este corpo-problema é um produto da mente e, enquanto tal, um produto com o seu grau de autonomia capaz de gerar novos paradigmas. Esta será pelo menos a perspetiva de Karl Popper e a sua conceptualização do mundo 3. Na sua teoria dos três mundos - uma tese metafísica de Popper (1996/2009) -, o mundo 3 tenta responder ao problema da relação corpomente.

0 "problema corpo-mente" nasce, segundo o autor, do relacionamento entre o mundo dos corpos físicos e respetivos estados fisiológicos, incluindo organismos (a que chama mundo 1) e o mundo dos estados ou processos mentais, experiências mentais conscientes (a que chama mundo 2). Admitindo-se pluralista, e não apenas dualista Popper responde com o mundo 3, um mundo terceiro que se apresenta como solução ao problema do corpo-mente, o mundo dos produtos da mente humana (teorias). Apesar de desenvolver estudos na área da Filosofia da Ciência, Popper dedica no seu livro 0 conhecimento e o problema corpo-mente (2009) várias páginas às artes e dá o exemplo da escultura como pertença simultaneamente do mundo 1 e do mundo 3. Não sendo o centro da nossa reflexão, não nos iremos alongar na exposição desta teoria, mas notamos que para uma discussão da materialidade da dança, haveria, então, que considerar a sua dimensão imaterial, em parte porque a dança não obriga a um suporte material prévio, mas também porque a dança é foco e desfoque (para usar uma imagem) da mesma matéria que é o corpo ora gesto ora pensamento. Nesta sua imaterialidade, a dança encontra o seu paradoxo ao ser evidência do mundo 1, do mundo físico, para usar a categoria de Popper, ao mesmo tempo que dele se distancia Não será, contudo, novidade que é a partir do momento em que se toma a dança como algo que não está exclusivamente no mundo 1 (o físico) e que é produto da mente (mundo 3, o crítico), que se apreende a sua real complexidade e que se questiona a sua evolução e o seu valor de ação.

0 mundo 3 é "o universo dos produtos da mente humana" (ibid.: 56) que podem ser tanto imateriais (argumentos, teorias, problemas) como, por vezes, físicos, materiais. Mas há ainda, segundo o autor, outros produtos da mente, nomeadamente artísticos, que não constituem propriamente coisas fisicas, por exemplo, uma peça de Shakespeare. Segundo Popper: "Um Hamlet, em livro escrito ou impresso, é uma entidade física como, digamos, um desenho. Mas a peça representada não é por certo uma coisa fisica, embora talvez se possa dizer que é uma sequência muitíssimo complexa de ocorrências físicas" (ibid:: 19). Está aqui em causa não só reconhecer-se a diferença entre o texto escrito e a representação da peça, como também as diferentes interpretações e representações da mesma peça. É a performatividade que aqui se problematiza na sua circulação física e imaterial.

0 que nos interessa sobretudo deste mundo 3 é que ele prevê produtos "autónomos", ou seja, produtos residentes no mundo 3 e que são "os problemas por resolver que emergem deste próprio mundo sem contribuirmos para o seu aparecimento e que se furtam ao nosso domínio" (ibid.: 53). Estes novos problemas surgem como consequências não intencionais dos produtos da mente, e por isso, são, segundo Popper, produtos mentais indiretamente. Ou seja, são os efeitos involuntários ou consequências não intencionais que podem gerar novos potenciais sobre as obras e que em muito podem transcender o ponto de partida e a intenção inicial. A promessa de um novo corpo nesta perspetiva é esta confirmação de um novo mundo impensado que nasce pelo feito, o que simplesmente se produziu, o que aconteceu.

A arte e, em particular, a dança contemporânea estão recheadas de matéria que é gerada a partir deste explorar de novas zonas de ação onde o corpo se protagoniza ou, ainda, na exploração de gestos desviantes a padrões, e é neste processo, que se constitui como um desafio, que 
surgem novas e impensadas soluções e desenlaces criativos. Há um mundo silencioso de problemas que existem independentemente da consciência que temos deles. É neste regime, em que a obra transcende o artista, que a criação artística se afasta da ideia de autoexpressão ou de uma inspiração associada aos estados fisiológicos ou "inconsciente".

Há, portanto, um plano de objetivação necessário e que é responsável, não só pelo agir, como pelo pensar a dança ou as artes performativas. Há também uma tangibilidade material a considerar e que se gera na construção do corpo dançante, isto é, o plano prédramatúrgico, o esquema de improvisação ou a micro composição que podem ou não nascer de efeitos involuntários mas que em todo o caso se fazem "reescrita" do corpo. Este plano, que pode ser estratégico, é principalmente um plano de tangibilidade material que faz a ponte entre a dimensão teórica e a dimensão prática da dança, conferindo à teoria um valor de instrumento. É ao nivel destes processos de construção - prédramatúrgico, esquema improvisativo ou de micro composição - que melhor se podem rever as mudanças relevantes na prática artística contemporânea, em particular no que esses processos podem responder às seguintes questões: qual é, afinal, a matéria da dança? E o que a dança pode dizer do mundo?'

0 corpo dançante é "objeto" na medida em que o questiono, o coloco como um problema - esta é a afetação necessária que o justifica como assunto teórico. Tudo o que se questiona fica em estado de suspensão, e é aqui que a dança contemporânea descobre a imobilidade, uma imobilidade que se cola a todo o corpo dançante. Esta é a complexidade com que o corpo se apresenta aos agentes da dança e, doravante, é esta a matéria da dança à qual se terá de responder. Percebe-se nestas questões a urgência que os criadores têm em fazer da dança um novo lugar que devolve mundo ao mundo. 0 corpo também, aqui, se torna um problema porque precisa de se debater diretamente com as suas representações. 0 corpo-problema é esta matéria que agora precisa de ser revisto e à qual as poéticas da dança contemporânea respondem pelo menos de dois modos. Por um lado, com o desvincular do corpo de uma dança nascida da ideia, isto é, um corpo que já não é mais veículo de formas ideais e que mimetiza as representações estabelecidas. Por outro lado, realizando uma indisjunção que consiste em entender o corpo físico, na sua mobilidade própria, como ser já dançante (isto é, a conceptualização do dançante recupera aqui o corpo que até agora não era treinado e sem o cunho de especial). São enormes as implicações da articulação destas possibilidades. Ao mesmo tempo que o corpo dançante se aproxima do corpo social enquanto singularidade, enquanto evento, e da mundanidade, enquanto lugar no mundo, o corpo dançante é objeto de circulação entre estado físico e a sua realidade feita problema.

Se podemos pensar em "forma" quando nos reportamos à dança, aquela terá de emergir como "produto" desta circulação. Já não se trata de pensar uma estética da forma que se dá no antagonismo entre forma sensivel e forma inteligivel, ou de uma noção de forma que nos arrasta no seu movimento no sentido da transcendência. Se anteriormente falávamos em integrar as tensões na forma e de não as moralizar ou dar-lhes um remate, agora trata-se de não tentar superar o efémero, cunhando-o de transcendência, mas sim de o reequacionar numa noção de forma que o revele e, principalmente, de pensar a forma como um produto material ou imaterial, nascido diretamente ou indiretamente da intencionalidade, fruto direto de uma ação consciente ou fruto impensado e que agora age sobre o corpo. É este complexo, este estado plural e o espaço onde se difere que carateriza a realidade que passa a ser desafio consciente às poéticas contemporâneas na arte.

\section{Identidade radical: primeiro movimento ético} Se a problematização ao nivel de um regime estético e poético transmuta o corpo problema em espaços de indiferenciação e diferimento, de liberdade e de autonomia, ao nível ético ele transforma-se sobretudo num "corpocom-direitos". Como se explica este aparente salto? Há uma dimensão imaterial e, porque não, metafísica deste corpo-problema enquanto produto da mente ao qual se augura eventualmente um desenlace concreto mas que entretanto é capaz de se multiplicar em novas questões, impensadas. E há uma dimensão física deste corpoproblema que é aquela onde o problema se gera de modo particular em regime de "situação" e de "interação". Que corpo é este e como o processo como matéria? Como me sociabilizo com o outro durante o processo criativo? Há uma negociação silenciosa que aguarda uma saída e que precede ainda um qualquer normativo. Esta chamada ética ao processo de criação é algo que a prática da dança contemporânea tem vindo a responder ao perceber a dimensão implicada e mesmo miscigenada da ética em qualquer "produção", em qualquer poética.

Uma das críticas que tem surgido ao entendimento da ética (Badiou ou Rancière, por exemplo) passa pelo facto de a ética estar muitas vezes alicerçada em categorias abstratas e maiores, tais como o Outro, a Decisão etc., ou de a ética dar uma resposta às tensões que possam existir na interação com o outro ou com a própria obra. A ética deveria, pelo contrário, limitar-se a expor tensões e a
Estas questões são já sinais da resistência, de que falávamos, a uma estética da forma tal como alguns a conceberam. Veremos, contudo, que é de uma relação formal que se irá tratar; por agora, discutilas-emos num âmbito estético e poético e depois num âmbito ético. 
focar-se em situações singulares por forma a não suprimir nem a política nem a arte e deixar que o "indecidivel" faça parte da própria obra.

No entanto, seria, porventura, sob o signo de uma "identidade radical", noção tomada de empréstimo à Estética da Formatividade de Luigi Pareyson ${ }^{2}$, que, segundo nós, se poderia repensar um estatuto ontológico da dança compativel com as diversas dimensões do fazer, das poéticas, e onde a ética estaria incluída. A questão do estatuto ontológico da arte em Pareyson, entende-se enquanto alteridade irredutivel, não dedutivel e não explicável por condições preexistentes. A autonomia da arte surge em parte desta indissociação entre a obra e o gesto que se implica por um "modo de formar" e há um mundo próprio que com este se origina. Um dos aspetos importantes neste modo de formar é que ele singulariza a obra e define o seu modo de ser. Isto é, a expressividade e comunicabilidade da obra não se reflete apenas pelos seus assuntos ou temas discursivos, mas enquanto os concretiza em si como "modo". A forma artística é matéria formada que por sua vez é matéria humanizada, espiritualizada, impregnada de significado e de expressividade. Note-se que esta identidade não resulta de uma dualidade entre forma e conteúdo, mas sim enquanto forma que é ao mesmo tempo "matéria formada" a ética da forma é o espaço necessário para que essas mesmas figuras se recomponham após um olharpensamento sobre o gesto ou sobre o outro. Este "olhar" não é mais que um abrandar ou, se quisermos, uma fenda que permita resistir aos consensos e às vicissitudes da comunicação e do contacto com o outro. 0 objetivo deste abrandamento será extrair qualquer ideologia a esta dimensão ética da forma (a condição para que se processe uma resposta decorrente das premissas referidas) de modo a que ela funcione como um protocolo silencioso através do qual se produzem os múltiplos outros e como alteridade da obra frente a seu autor e ao seu tempo.

\section{Reconfigurações do corpo}

Ao longo deste texto demos particular importância ao complexo que é o corpo como um problema enquanto dispositivo teórico que se implica na exploração de novas formas dançantes. Este foi identificado como o desafio que tem guiado as artes performativas na contemporaneidade. Para tal, recorrendo a uma heterogeneidade de autores e aos seus contributos, consideramos importante ativar a discussão em torno de duas dimensões inerentes a este corpo-problema: a dimensão teórica associada à "produção"; a sua correspondência à "autonomia" da arte. Estas dimensões ao contribuírem para o reconhecimento dos novos mundos que nascem com a obra, ao mesmo tempo que reconhecem o carácter permanente da sua condição de receção, reconfiguram-se como a dimensão ontológica do corpo dançante e da sua política da forma. A promessa de um novo corpo que desponta no estético e no politico, segundo um regime do sensivel, é ainda promessa que se mantem pela impensabilidade que ocorre em cada ato, em cada produção. Na suspensão do curso do mundo e das ideologias, na objetivação ou nas novas interrogações sobre o mundo, a imobilidade que a estes processos se associa é uma positividade da promessa de um corpo outro.

\section{Referências bibliográficas}

BADIOU, Alain (2003), L'éthique: Essai sur la conscience du mal, Caen, Nous. PAREYSON, Luigi (1988), Estetica: Teoria della formativitá, Milano, Tascabili Bompiani, [2. ${ }^{\text {e ed. 1991]. }}$

POPPER, Karl (1996), O conhecimento e o problema corpo-mente, tradução de Joaquim Alberto Ferreira Gomes, Lisboa, Edições 70, [2009]

RANCIĖRE, Jacques (2000), "What aesthetics can mean", in Peter Osborne (ed.), From an Aesthetic Point of View, Londres, Serpent's Tail, pp.1333.

-- (2005), Situação \#3 Estética e Politica, "São Paulo S.A. Práticas Estéticas, Sociais e Politicas em debate", Sesc Belenzinho, São Paulo.

\footnotetext{
e "conteúdo expresso". A identidade da obra é dada por uma composição que integra o gesto criativo e a lei orgânica que presidiu ao processo criativo.

A identidade, nesta perspetiva, é pura organicidade resultante de um entendimento de que na obra se plasma toda a realidade que the deu origem. Como poderiamos então entender uma identidade radical reportada à dança? Para além da evidente indissociação do autoral gesto criativo com a obra produto autónomo, há um novo corpo emergente do corpo-problema que é um corpo onde se manifestam tensões, dissensos, um corpo dispositivo e implicativo, ou seja, uma nova entidade que surge e que não é já matéria abstrata mas também não é uma matéria de consensos. Esta nova entidade é, para nós, o "corpocom-direitos", não o direito no sentido abstrato mas na sua ligação ao corpo como lugar da resistência e da singularidade e também da situação e da interação. É esta a nova realidade da matéria de que se faz a dança e que ao fazer-se dança declara a sua própria "condição".

Se ao corpo problema associáramos um atractor teleológico da obra em si, o corpo-com-direitos é a exibição depurada de uma dada condição do indivíduo (o comunitário) na sua prática. Esta exposição graciosa é aquela que emerge ao nivel pré-dramatúrgico, esquema improvisativo ou de micro composição, como anteriormente referimos, e onde se reconfigura uma "ética da forma". Num jogo de distâncias entre nós e as figuras do mundo,

capaz de conferir "identidade radical".

realidade de arte $E e_{\text {, }}$

através de uma relação
} 